\title{
Airloads Correlation of the UH-60A Rotor Inside the 40- by 80-Foot Wind Tunnel
}

\author{
I-Chung Chang ${ }^{1}$, Thomas R. Norman ${ }^{2}$, and Ethan A. Romander ${ }^{3}$ \\ Flight Vehicle Research and Technology Division, NASA Ames Research Center, Moffett Field, CA 94035
}

The presented research validates the capability of a loosely-coupled computational fluid dynamics (CFD) and comprehensive rotorcraft analysis (CRA) code to calculate the flowfield around a rotor and test stand mounted inside a wind tunnel. The CFD/CRA predictions for the full-scale UH-60A Airloads Rotor inside the National Full-Scale Aerodynamics Complex (NFAC) $\mathbf{4 0 -}$ by $\mathbf{8 0 - F o o t ~ W i n d ~ T u n n e l ~ a t ~ N A S A ~ A m e s ~ R e s e a r c h ~}$ Center are compared with the latest measured airloads and performance data. The studied conditions include a speed sweep at constant lift up to an advance ratio of 0.4 and a thrust sweep at constant speed up to and including stall. For the speed sweep, wind tunnel modeling becomes important at advance ratios greater than 0.37 and test stand modeling becomes increasingly important as the advance ratio increases. For the thrust sweep, both the wind tunnel and test stand modeling become important as the rotor approaches stall. Despite the beneficial effects of modeling the wind tunnel and test stand, the new models do not completely resolve the current airload discrepancies between prediction and experiment.

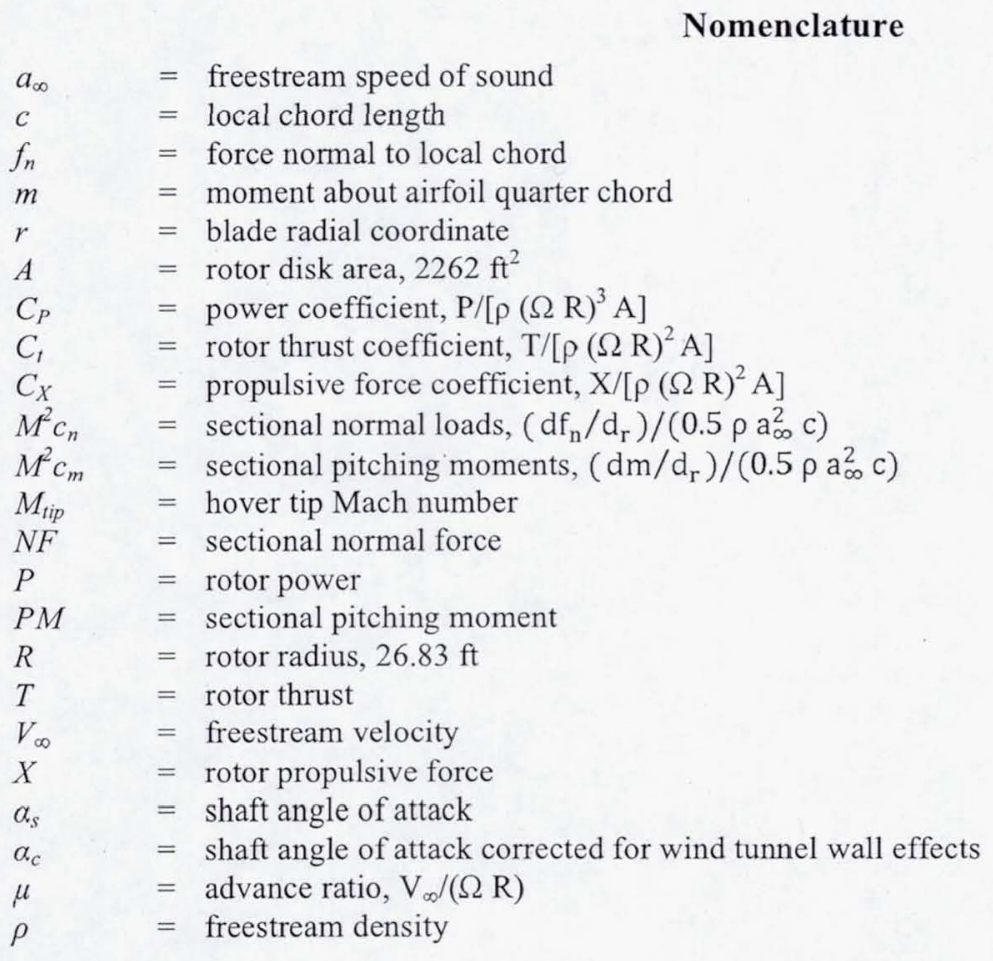

\footnotetext{
${ }^{1}$ Aerospace Engineer, Flight Vehicle Research and Technology Division, Mail Stop 243-12, and AIAA Member.

${ }^{2}$ Aerospace Engineer, Flight Vehicle Research and Technology Division, Mail Stop 243-12.

${ }^{3}$ Aerospace Engineer, Flight Vehicle Research and Technology Division, Mail Stop 243-12. 


$\begin{array}{lll}\sigma & = & \text { rotor solidity, } 0.0826 \\ \theta_{0} & =\text { collective angle, deg } \\ \theta_{l c} & =\text { lateral cyclic, deg } \\ \theta_{l s} & =\text { longitudinal cyclic, deg } \\ \Omega & =\text { rotor angular velocity }\end{array}$

\section{Introduction}

A CCURATE and efficient helicopter flow-field and airloads prediction is a challenge for CFD research. The Aflow-field is unsteady, three-dimensional, with transonic flow on the advancing blade, dynamic stall on the retreating blade, blade-vortex interactions (BVI), and vortical wakes. In addition, rotor blades are subjected to complex aero-elastic interactions and elastic deflections. Ultimately, a multi-disciplinary approach is needed to satisfactorily simulate the vehicle and flow-field. One such approach involves the coupling of computational fluid dynamics (CFD) and comprehensive rotorcraft analysis (CRA) codes.

One of the first attempts to couple CFD and CRA codes was described by Tung, Caradonna, and Johnson ${ }^{1}$, using a transonic small disturbance flow code (FDR) and a comprehensive rotorcraft analysis code (CAMRAD). Other transonic small disturbance (TSD) $\operatorname{codes}^{2}$ and full-potential flow (FP) codes ${ }^{3-5}$ were later coupled by researchers with not only the CAMRAD code but also other comprehensive rotorcraft codes. In this methodology, the CFD code requires not only blade deflections but also inflow angles from the comprehensive rotorcraft analysis code to account for rotor blade structural deformation and the influence of the vortical wakes outside the very small CFD computational domain (usually limited to the outboard portion of the blade and a few chords away). Issues were encountered and overcome with the convergence of the coupled code as well as accurately estimating the rotor inflow angles.

With the continuing advancement of computational power, it has become possible to use both Euler codes ${ }^{6}$ and/or Navier-Stokes CFD $\operatorname{codes}^{7-10}$ for the CFD portion of the coupled CFD/CRA toolset. The prediction of full domain rotor wakes in these codes no longer requires the added complexity of estimating inflow angles outside the computational domain, instead relying on a direct simulation of the entire flow field. One of the best examples in this category was the coupled code developed by Potsdam, Yeo, and Johnson ${ }^{11}$, using the CFD code OVERFLOW$\mathrm{D}^{12}$ and the CRA code CAMRAD $\mathrm{II}^{13}$. The coupling methodology outlined in this effort has become a standard for the prediction of rotor aeromechanics.

A new validation dataset has recently become available to evaluate the capabilities of these new predictive tools. This dataset comes from a test of a full-scale UH-60A airloads rotor system in the USAF's National Full-Scale Aerodynamics Complex (NFAC) 40 - by 80 -Foot Wind Tunnel ${ }^{14}$. Figure 1 shows the system in the wind tunnel with the rotor mounted on the Large Rotor Test Apparatus (LRTA). The primary objective of this test program was to acquire a comprehensive set of validation-quality measurements on a full-scale pressure instrumented rotor system at conditions that challenged the most sophisticated modeling and simulation tools. A second objective was to meet one of the original goals of the UH-60A Airloads Program ${ }^{15}$ : to provide data to evaluate the similarity, or lack thereof, of measurements between small-scale wind tunnel ${ }^{16,17}$, full-scale wind tunnel, and full-scale flight test ${ }^{18,19}$. Key measurements included rotor performance, blade structural loads, blade pressures and airloads, blade displacements, and measurements of the rotor wake. Data were acquired over a wide range of test conditions, including speed sweeps at $1-\mathrm{g}$ simulated flight conditions and parametric thrust sweeps up to and including stall. In addition, data were acquired at conditions from the previous full-scale flight test and small-scale wind tunnel test to assess both wind tunnel and scaling effects ${ }^{20}$.

Correlations of this new validation data with predictions from various CFD/CRA coupled codes are an active research area. Recent efforts have focused on validation of rotor airloads ${ }^{21}$ and blade structural loads ${ }^{22}$ by simulating the UH-60A as an isolated rotor in free air (wind tunnel wall effects are accounted for with a shaft angle correction). Although the initial correlations have been promising, differences between measured and predicted airloads remain. One possible cause for these differences is the simplified CFD modeling of the wind tunnel configuration as an isolated rotor. In the current research, the wind tunnel walls and LRTA test stand have been modeled directly to investigate their effects on the predicted loads and to assess the flight conditions at which more sophisticated modeling may be necessary. This effort extends previous wind tunnel modeling ${ }^{23}$ and applies it to correlations with the measured wind tunnel data. 


\section{Prediction Methodology}

The computational method used in this study was derived from the OVERFLOW-D and CAMRAD II coupling methods described in Ref. 11 for a rotor in free air and is similar to that used in Refs. 21 and 22. It incorporates updated versions of OVERFLOW $2^{12}$ and CAMRAD II ${ }^{13}$ combined through a loose coupling approach. In addition, the method includes the wind tunnel and test stand modeling first introduced in Ref. 23 to simulate the flow field in a wind tunnel. A description of each of these elements is provided in the following section, along with a description of the trim targets and convergence criteria used in this study.

\section{A. CAMRAD II}

Structural dynamics and rotor trim for the coupled analysis were performed using the comprehensive rotorcraft analysis code CAMRAD II. This code brings together a multi-body dynamics model, a nonlinear finite-elements structural model, and an aerodynamics model based on lifting line theory. For the present effort, the CAMRAD II structural model for the UH-60A simulated the rotor using seven 1-D structural beam elements and twenty aerodynamic panels. The rotor aerodynamic and structural property inputs were consistent with previously presented results ${ }^{11,21,23}$. The rotor was trimmed using a Newton-Raphson iterative scheme on collective and cyclic angles to meet specified trim targets.

\section{B. OVERFLOW2}

The CFD module used in this effort was the Reynolds-averaged Navier-Stokes flow solver, OVERFLOW2 version $2.2 \mathrm{~b}$. It is an overset, structured-mesh flow solver that offers a wide variety of numerical schemes, turbulence models, and boundary conditions as user-defined options. For the present study, OVERFLOW2 was run with $2^{\text {nd }}$ order central differencing and $2^{\text {nd }}$ and $4^{\text {th }}$ order artificial dissipation in space, and an implicit $2^{\text {nd }}$ order temporal scheme with up to 40 sub-iterations for each time step. The sub-iteration scheme allowed a bigger time step while maintaining numerical stability. Turbulence was modeled near blade surfaces using the Spalart-Almaras one-equation model ${ }^{24}$. Uniform free-stream conditions were prescribed at the tunnel entrance plane and a conservation of mass condition was enforced at the tunnel exit plane (similar to Ref. 25). Flow through the tunnel was modeled as inviscid with flow tangency enforced at the walls.

\section{CFD Grid}

Computational grids for OVERFLOW are generally divided into two categories, with near-body grids representing the fuselage and rotor surfaces and surrounding off-body grids that capture wake flow. Both the freeair and rotor-in-tunnel simulations presented here used the same set of grids to represent the rotor. Some in-tunnel simulations also included a set of grids to represent the LRTA test stand. The complete near-body grid set is depicted in Fig. 2.

Fifteen near-body grids were used to model the rotor itself. The first 12 grids described the UH-60A rotor, with three grids (blade, root cap, and tip cap) for each of the four blades. These near-body grids extended approximately one chord length from the surface and included sufficient resolution to capture boundary layer viscous effects. The main blade grid featured an O-mesh topology (replacing the C-mesh of Ref. 23), with main blade mesh-point dimensions of $163 \times 115 \times 80$ (chordwise, radial, and normal directions). The final three rotor grids defined a notional hub. In total, these rotor grids contained approximately 10.7 million points.

The 8 near-body grids modeling the LRTA test stand could be added or removed from the simulation without altering the rotor or off-body grids. The total number of mesh points for the LRTA model was 7.4 million.

Free-air simulations consisted of near-body grids for the rotor only (no LRTA) and an off-body grid set composed of uniform Cartesian blocks. The off-body set was arranged in shells around the rotor denoted as level 1 to 5 . The level 1 grid was a single block slightly larger that the rotor disk and extending slightly above and several chord lengths below (Fig. 3). The spacing in this block was $10 \%$ of the chord length of the rotor and was constant in all three directions. Each successive layer enclosed the former and had spacing twice that of the preceding layer. The far edges of the level 5 grid were 5 rotor radii from the hub and defined the edge of the computational domain.

The wind tunnel was modeled in a simplified sense as a straight tunnel section of length 247.6 feet with the cross section dimensions exactly as that of the test section. The UH-60A rotor hub center was located at the center of the cross plane, 123.9 feet down-stream from the wind tunnel entrance plane. The wind tunnel grid had mesh-point dimensions of $208 \times 206 \times 99$ (streamwise, lateral, vertical). The mesh points of the wind tunnel grid were not evenly distributed but rather were clustered near the rotor. In an effort to eliminate grid effects on the captured wake, the

3

American Institute of Aeronautics and Astronautics 
level 1 and 2 grids from a free-air simulation were extracted and used to convect the flow between the rotor and tunnel grids. Figures 3 and 4 show a representation of the rotor and LRTA inside the wind tunnel.

\section{Loose Coupling Approach}

The fundamental concept of the loose coupling procedure ${ }^{1,11}$ is that the methodology replaces the airloads of a comprehensive rotorcraft analysis code with the airloads predicted by a CFD code in an iterative way, while using a lifting line aerodynamic analysis to trim the rotor and a blade dynamic analysis to predict rotor blade deformation motion. In addition, it is assumed that all four blades are structurally and aerodynamically identical and therefore undergo the same blade motion. A detailed description of this approach for the first and all subsequent iterations is provided below.

\section{Oth Coupling iteration}

An initial CAMRAD II run is performed assuming rigid blades in a vacuum (no wind). This run establishes the blade motion baseline for future CAMRAD II runs. The resultant output is identified as the rigid blade solution. A second CAMRAD II run is then performed using flexible blades and the lifting line aerodynamic analysis, resulting in a trimmed rotor solution. The difference in blade position between the rigid and trimmed solutions defines the initial blade motions to be transferred to the OVERFLOW2 code. Because OVERFLOW2 models the entire rotor domain, including all blades and full wakes, there are no other required inputs from the CAMRAD II code to the OVERFLOW2 code. This eliminates the need for ad hoc inflow angles or induced velocity effects as required in earlier work with potential flow codes, or Navier-Stokes codes with partial flow-domain methodologies.

The OVERFLOW2 code is run using the CAMRAD II specified blade motions. This initial CFD solution need not be fully converged; typically, one full rotor revolution (360 deg) is sufficient. OVERFLOW2 outputs normal force, pitching moment, and chordwise force as a function of radius and azimuth at user-specified intervals, typically at one degree azimuth increment. These forces and moments are then passed back to CAMRAD II for the next coupling iteration.

\section{Nth Coupling Iteration}

Airloads for every $15^{\circ}$ are extracted from the OVERFLOW2 solution. For a 4-bladed rotor, only one quarter of a revolution $(90 \mathrm{deg}$ ) is sufficient because each blade sweeps through a quadrant in that time. The differences between OVERFLOW2 airloads and CAMRAD II airloads from the previous coupling iteration are called the airload deltas, and are the corrections to the lifting line solution. CAMRAD II is run again using the lifting line aerodynamic analysis, resulting in a re-trimmed rotor solution. The new CAMRAD II airloads are the current CAMRAD II lifting line airloads plus a correction based on the OVERFLOW2 solution, i.e. the airload deltas.

New blade motions are computed using the re-trimmed rotor solution and the original rigid blade solution. OVERFLOW2 is run with the new blade motions, marking the start of another coupling iteration.

This coupling iteration is repeated several times until the collective and cyclic angles in the CAMRAD II code, and the OVERFLOW2 predicted aerodynamic forces, do not change significantly between two iterations.

\section{E. Trim Targets}

In this study, the CAMRAD II code was used to trim the rotor system at each flight condition. In each case, CAMRAD II solved for the collective and cyclic controls necessary to attain a specified rotor thrust, hub roll moment, and hub pitch moment at a prescribed rotor shaft angle. Namely, the collective and cyclic controls were determined during the trim procedures while rotor thrust and hub moments were constrained to prescribed values in the coupling iterative process.

\section{F. Solution Convergence}

A total of one $0^{\text {th }}$ coupling iteration and $12 \mathrm{n}^{\text {th }}$ coupling iterations were run for each CFD/CRA prediction in this study. One full rotor revolution of CFD solution was required for the initial $0^{\text {th }}$ coupling and one quarter revolution of CFD solution was required for each $\mathrm{n}^{\text {th }}$ coupling iteration. This resulted in a total of 4 full rotor revolutions for each solution. Both the CFD and CRA convergence history data were checked to make sure that the entire CFD/CRA simulation converged successfully at each flight condition. Representative examples of convergence history are shown in Figs. 5 and 6 for one of the most difficult cases from this study (a deep stall condition). Figure

4

American Institute of Aeronautics and Astronautics 
5 shows the normal forces and pitch moments from OVERFLOW2 and Fig. 6 shows the collective and cyclic control angles from CAMRAD II (normalized by their final values). Both figures indicate that the solutions have satisfactorily converged within 12 iterations even for this challenging condition.

\section{Results}

As described above, the objective of this study was to investigate the effects of modeling the wind tunnel walls and LRTA test stand on the predicted UH-60A rotor airloads. To accomplish this, CFD/CRA predictions for the fullscale UH-60A rotor inside the 40 - by 80 -Foot Wind Tunnel are compared with the latest measured data ${ }^{14,20}$. The studied conditions include a speed sweep at constant lift, a thrust sweep at constant speed, and an investigation of a single matched flight test condition. In the following section, rotor airload measurements are compared with predictions from three different CFD configurations; a) rotor only in free air, b) rotor and wind tunnel, and c) rotor, LRTA, and wind tunnel. In addition, selected rotor performance data are compared for both the speed and thrust sweep.

\section{A. Speed Sweep (Run 52)}

The wind tunnel speed sweep selected for comparison included data acquired over a range of advance ratios $(\mu=$ 0.15 to 0.40$)$ at constant thrust/lift $\left(\mathrm{C}_{\mathrm{t}} / \sigma=0.09\right)$ and hover tip Mach number $\left(\mathrm{M}_{\text {tip }}=0.65\right)$. Predictions were made at conditions matching the five advance ratio cases shown in Table 1. Airload comparisons will be presented for the low and high speed cases and performance comparisons will be made using data from all cases.

\section{Low Speed Case, $\mu=0.15$ (Run 52, Point 15)}

The effects of the three modeling configurations on the predicted rotor airloads for this low-speed condition can be seen in Figs. 7-10. Figure 7 plots the predicted normal force and pitch moment distributions from the rotor/wind tunnel simulation (Prediction-WT, purple curves) against the NFAC test data (Test-NFAC, blue curves) at three radial stations, $r / R=0.4,0.865$ and 0.92 . This comparison shows that the measured normal force distributions are reasonably well predicted, although some of the higher-frequency, blade-vortex-interaction events on the advancing side are underpredicted. The measured pitch moment distributions are not as well captured, with some variations in steady values as well as the higher frequency events. Despite these differences, the results provide confidence that the extension of the loosely-coupled CFD/CRA code to the wind tunnel environment was generally successful.

To help evaluate the effects of modeling the wind tunnel, airload predictions from the rotor/wind tunnel and rotor only modeling are compared in Fig. 8. For the rotor only computations, a corrected shaft angle $\left(\alpha_{c}\right)$ was used as input to roughly account for the effects of the wind tunnel walls (similar to the procedure used in Refs. 21 and 22). This corrected angle was estimated with a Glauert-type correction ${ }^{26,27}$, which determines the average upwash effect of the wind tunnel walls (based on rotor and tunnel geometry, rotor lift, and tunnel speed). The net shaft angle correction for this low-speed flight condition was nearly $2.8 \mathrm{deg}$ (see Table 1). Comparisons of the rotor/wind tunnel (Prediction-WT, purple curves) and rotor only (Prediction-Glauert, green curves) predictions in Fig. 8 show very few differences in the airloads. This suggests that although the Glauert-type shaft angle correction is only a first order approximation for the wind tunnel wall effects, it appears to provide excellent results for this test condition.

To help evaluate the effects of modeling the LRTA test stand, airload predictions from the rotor/wind tunnel (Prediction-WT, purple curves) and rotor/LRTA/wind tunnel (Prediction-WT/LRTA, red curves) modeling are compared in Fig. 9. Small but noticeable differences in normal force are seen on the advancing side at the outboard radial stations, and over the nose and tail at the inboard station. Very little difference is seen in the pitching moments. In general, the effect of the LRTA on airloads is small at this low-speed test condition.

The results from Figs. 7-9 are combined onto a single plot in Fig. 10. This figure includes the NFAC test data as well as all predicted normal force and pitch moment distributions for the three different CFD configurations. This type of figure will serve as the standard plot for presenting comparisons of predicted sectional airloads and NFAC test data for all remaining cases. For the low-speed case shown here, the modeling of the LRTA and wind tunnel have only a small effect on predicted airloads and do not significantly improve the overall prediction accuracy.

\section{High Speed Case, $\mu=0.40$ (Run 52, Point 51)}

Figure 11 plots the predicted normal force and pitch moment distributions for the three different CFD configurations against NFAC test data for the high-speed case. In general, the trends in normal force and pitch moment distributions are better correlated with NFAC data at this condition. 
Compared with the low-speed case, there are much larger differences between the rotor only and rotor/wind tunnel predictions for both normal force and pitching moment. This is most apparent for normal force on the advancing side for all three radial stations and for pitching moment at $r / R=0.40$ and 0.92 . Of particular note is how the rotor/wind tunnel modeling begins to pick up the pitching moment dip near $320^{\circ} \mathrm{at} r / \mathrm{R}=0.92$. These differences suggest that the simple Glauert correction may not be adequate at this high-speed condition.

The differences between predictions for rotor/wind tunnel and rotor/LRTA/wind tunnel modeling help show the effect of the LRTA on airloads. Similar to the low-speed case, noticeable differences in normal force are seen on the advancing side at the outboard radial stations, and over the nose and tail at the inboard station. In addition, differences in pitching moment have become apparent at both $\mathrm{r} / \mathrm{R}=0.4$ and 0.92 , especially on the retreating side. This includes a significant pitching moment dip near $200^{\circ}$ at $r / R=0.4$ which better matches the wind tunnel data. The effects of the LRTA have clearly become more significant at this condition.

For this high-speed case, the modeling of the LRTA and wind tunnel has a pronounced effect on the predicted airloads and has been shown to better predict some key features found in the experimental data. Further examination of airload comparisons at other advance ratios (not shown) indicates that wind tunnel modeling becomes important at advance ratios greater than $\mu=0.37$ and that LRTA modeling becomes increasingly important as the advance ratio increases. Nonetheless, this modeling does not completely resolve the current discrepancies between prediction and experiment.

\section{Performance Results}

Rotor performance comparisons between NFAC test data and rotor/wind tunnel predictions for the speed sweep are provided in Fig. 12. These include comparisons of rotor thrust, propulsive force and power as a function of advance ratio. The rotor thrust (computed in OVERFLOW2) was nominally 2.5 percent higher than the measured values for all speeds. This difference is consistent with the results from Refs. 21 and 22 and has been attributed to force conservation issues between CAMRAD II and OVERFLOW2. Based on the results from these earlier studies, this small thrust difference is not expected to have a significant effect on the overall results. In addition to the thrust results, the propulsive force is slightly underpredicted and the rotor power is very well predicted for all advance ratios. These results are consistent with previous results and once again suggest that the extension of the UH-60A modeling to the wind tunnel environment has been successful.

\section{B. Thrust Sweep (Run 45)}

The wind tunnel thrust sweep selected for comparison included data acquired over a range of thrust coefficients $(\mathrm{Ct} / \sigma=0.02$ to 0.1255$)$ at constant advance ratio $(\mu=0.3)$, hover tip Mach number $\left(\mathrm{M}_{\text {tip }}=0.625\right)$, and geometric shaft angle $\left(\alpha_{s}=0 \mathrm{deg}\right)$. Predictions were made at conditions matching the six thrust cases shown in Table 2. Airload comparisons will be presented for moderate and high thrust cases and performance comparisons will be made using data from all cases.

1. Moderate Thrust Case, $C_{t} / \sigma=0.09$ (Run 45, Point 33)

Figure 13 plots the predicted normal force and pitch moment distributions for the three different CFD configurations against NFAC test data for the moderate thrust case. Overall correlation of the three simulation results with NFAC test data is generally good.

Comparisons of the rotor/wind tunnel and rotor only predictions show very few differences in the airloads. This is not surprising considering the conclusions from the speed sweep above. Glauert-type shaft angle corrections provide excellent results at these conditions.

The effects of the LRTA modeling on the airloads predictions are also consistent with previous results. Effects on normal force are found on the advancing side at the outboard radial stations, and over the nose and tail at the inboard station. The primary difference seen in pitching moment is the dip near $200^{\circ}$ at $\mathrm{r} / \mathrm{R}=0.4$.

\section{High Thrust Case, $C_{t} / \sigma=0.1255$ (Run 45, Point 38)}

Figure 14 plots the predicted normal force and pitch moment distributions for the three different CFD configurations against NFAC test data for the high thrust case. Overall correlations of the three CFD simulation results with NFAC test data are mixed. Many of the stall features on the retreating side are well captured, but neither the normal force nor pitching moment troughs on the advancing side of the outboard radial stations are adequately predicted.

6

American Institute of Aeronautics and Astronautics 
Compared with the moderate thrust case, there are much larger differences between the rotor only and rotor/wind tunnel predictions for both normal force and pitching moment. This is most apparent for normal force on the advancing side and for pitching moment on the retreating side for the outboard radial stations. Noticeable differences near $120^{\circ}$ (shocks) and $300^{\circ}$ (stall) suggest that some three-dimensional wind tunnel effects are missed by the Glauert shaft angle correction formula. Further investigation of this effect is recommended.

The differences between predictions for rotor/wind tunnel and rotor/LRTA/wind tunnel modeling help show the effect of the LRTA on airloads. Similar to the speed sweep results, noticeable differences in normal force are seen on the advancing side at the outboard radial stations, and over the nose and tail at the inboard station. In addition, differences in pitching moment can be seen in the magnitude of the dynamic stall events on the retreating side of the outboard sections, as well as the magnitude of the pitching moment dip near $200^{\circ}$ at $r / R=0.4$. The effects of LRTA modeling at this high thrust condition are clearly significant.

Similar to the high-speed case, the modeling of the LRTA and wind tunnel at high thrust has a pronounced effect on the predicted airloads. Further examination of airload comparisons at other thrust levels (not shown) indicates that wind tunnel modeling becomes important at thrust levels greater than $\mathrm{C}_{\mathrm{t}} / \sigma=0.11$ and that LRTA modeling becomes increasingly important at thrust levels greater than $\mathrm{C}_{\mathrm{t}} / \sigma=0.09$. Nonetheless, this modeling does not completely resolve the current discrepancies between prediction and experiment.

\section{Performance Results}

Rotor performance comparisons between NFAC test data and rotor/wind tunnel predictions for the thrust sweep are provided in Fig. 15. These include comparisons of rotor thrust, propulsive force and power as a function of measured rotor thrust. The results are similar to those from the speed sweep in that the thrust is slightly overpredicted and the propulsive force is slightly underpredicted, with larger variations at the higher thrust levels. The power is slightly overpredicted at low thrust and underpredicted at high thrust. Once again, these results are consistent with previous results ${ }^{21,22}$.

\section{Single Matched Flight Test Condition}

In a recent AHS Forum paper ${ }^{20}$, Norman and his associates compared the airloads from one NFAC wind tunnel test condition (Run 47, Point 21) with the airloads from a matched flight test condition (c8424 from the Airloads Flight Test). In particular they noted that, compared with flight test data, there was a reduced rate of change of normal force between 120 and $240 \mathrm{deg}$ azimuth at the outboard stations, and an increased rate of change of pitching moment in the same azimuth interval. The cause of these differences was not understood and it was suggested that CFD computations might provide some insight.

Figure 16 plots the predicted normal force and pitch moment distributions for the rotor only and rotor/wind tunnel CFD configurations against NFAC and flight-test data (Test-Flight, black curves) for the matched condition. The results suggest that the wind tunnel modeling does not have a significant effect at this condition and that the differences between wind tunnel and flight test are not likely to be caused by three-dimensional wind tunnel effects. Further investigation into other causes for the airload differences is required.

\section{Conclusions}

The objective of this study was to investigate the effects of adding new CFD models of the wind tunnel walls and test stand to the predictions of UH-60A Airloads wind tunnel data and to assess the test conditions at which the more sophisticated modeling may be necessary. To accomplish this, CFD/CRA predictions for the full-scale UH$60 \mathrm{~A}$ rotor inside the 40 - by 80 -Foot Wind Tunnel were compared with measured wind tunnel data for a speed sweep at constant lift, a thrust sweep at constant speed, and an investigation of a single matched flight test condition. Three different CFD configurations were considered; a) rotor only, b) rotor and wind tunnel, and c) rotor, LRTA, and wind tunnel.

Conclusions from this study include the following:

1) In general, rotor airloads and rotor performance are reasonably well predicted with the new models, and are consistent with previously presented results. These results provide confidence that the extension of the loosely coupled CFD/CRA code to the wind tunnel environment was successful.

2) From the speed sweep comparisons, it was found that modeling the LRTA and wind tunnel have only limited benefits at low speeds when compared to rotor only calculations using simple angle of attack 
corrections. Wind tunnel modeling becomes important at advance ratios greater than $\mu=0.37$ and LRTA modeling becomes increasingly important as the advance ratio increases.

3) From the thrust sweep comparisons, it was found that modeling the LRTA and wind tunnel at high thrust has a pronounced effect on the predicted airloads. Wind tunnel modeling becomes important at thrust levels greater than $\mathrm{C}_{\mathrm{t}} / \sigma=0.11$ and LRTA modeling becomes increasingly important at thrust levels greater than $\mathrm{C}_{\mathrm{t}} / \sigma=0.09$.

4) Despite the beneficial effects of modeling the LRTA and wind tunnel, the new models do not completely resolve the current discrepancies between prediction and experiment.

Future work will focus on improving the resolution of the grid systems, including the use of grid adaption algorithms for better wake capturing ${ }^{28}$.

\section{References}

${ }^{1}$ Tung, C., Caradonna, F. X., and Johnson, W. R., "The Prediction of Transonic Flows on an Advancing Rotor," American Helicopter Society $40^{\text {th }}$ Annual Forum, Arlington, VA, May 1984.

${ }^{2}$ Kim, K-C., Desopper, A., and Chopra, I., "Blade Response Calculations using Three-Dimensional Aerodynamic Modeling," Journal of the American Helicopter Society, Vol. 36, No. 1, pp.68-77, January 1991.

${ }^{3}$ Strawn, R. C., Desopper, A., Miller, M., and Jones, A., "Correction of PUMA Airloads - Evaluation of CFD Prediction Methods," Paper No. 14, $15^{\text {th }}$ European Rotorcraft Forum, Amsterdam, Netherlands, September 1989.

${ }^{4}$ Strawn, R. C., and Bridgeman, J. O., "An Improved Three-Dimensional Aerodynamics Model for Helicopter Airloads Prediction," AIAA Paper 91-0767, ALAA $29^{\text {th }}$ Aerospace Sciences Meeting and Exhibit, Reno, NV, January 1991.

${ }^{5}$ Beaumier, P., "A Coupling Procedure Between a Rotor Dynamics Code and a 3D Unsteady Full Potential Code," American

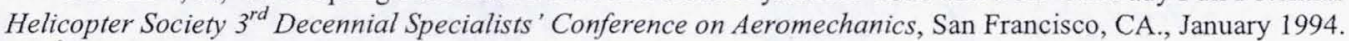

${ }^{6}$ Servera, G., Beaumier, P., and Costes, M., "A Weak Coupling Method Between the Dynamics Code Host and the 3D Unsteady Euler Code WAVES," $26^{\text {th }}$ European Rotorcraft Forum, The Hague, Netherlands, September 2000.

${ }^{7}$ Sitaraman, J., Baeder, J. D., and Chopra, I., "Validation of UH-60A Rotor Blade Aerodynamic Characteristics Using CFD," American Helicopter Society $59^{\text {th }}$ Annual Forum, Phoenix, AZ., May 2003.

${ }^{8}$ Sitaraman, J., Datta, A., Baeder, J. D., and Chopra, I., "Fundamental Understanding and Prediction of Rotor Vibratory Loads in High-Speed Forward Flight," $29^{\text {th }}$ European Rotorcraft Forum, Friedrichshafen, Germany, September 2003.

${ }^{9}$ Pahlke, K., and van der Wall, B., "Calculation of Multi-bladed Rotors in High-Speed Forward Flight With Weak FluidStructure Coupling," $27^{\text {th }}$ European Rotorcraft Forum, Moscow, Russia, September 2001.

${ }^{10}$ Datta, A., Sitaraman, J., Chopra, I., and Baeder, J. D., "Improved Comprehensive Analysis for Prediction of Rotor Vibratory Loads in High-Speed Forward Flight," American Helicopter Society $60^{\text {th }}$ Anmual Forum, Baltimore, MD, June 2004.

${ }^{11}$ Potsdam, M., Yeo, H., and Johnson, W., "Rotor Airloads Prediction using Loose Aerodynamics/Structural Coupling," American Helicopter Society $60^{\text {th }}$ Annual Forum, Baltimore, MD, June, 2004.

${ }^{12}$ Nichols, R. H., and Buning, P. G., User's Manual for OVERFLOW 2.1, August 2008.

${ }^{13}$ Johnson, W., "Rotorcraft Aerodynamic Models for a Comprehensive Analysis," American Helicopter Society $54^{\text {th }}$ Annual Forum, Washington, D. C., May 1998.

${ }^{14}$ Norman, T. R., Shinoda, P., Peterson, R. L., and Datta, A. "Full-Scale Wind Tunnel Test of the UH-60A Airloads Rotor," American Helicopter Society $67^{\text {th }}$ Annual Forum, Virginia Beach, VA, May 2011.

${ }^{15}$ Kufeld, R. M., and Bousman, W. G., "UH-60A Helicopter Rotor Airloads Measured in Flight," The Aeronautical Journal of the Royal Aeronautical Society, May 1997.

${ }^{16}$ Yu, Y. H., Liu, S. R., Landgrebe, A. J., Lorber, P. F., Pollack, M. J., Martin, R. M., and Jordan, D., "Aerodynamic and Acoustic Test of a United Technologies Model Scale Rotor at DNW," American Helicopter Society $46^{\text {th }}$ Anmual Forum, Washington, D. C., May 1990.

${ }^{17}$ Lorber, P. F., "Aerodynamic Results of a Pressure Instrumented Model Rotor Test at the DNW," Journal of American Helicopter Society, Vol. 36, (4), October 1991.

${ }^{18}$ Kufeld, R. M., Balough, D. L., Cross, J. L., Studebaker, K. F., Jennison, C. D., and Bousman, W. G., "Flight Test of the UH-60A Airloads Aircraft," American Helicopter Society 50 th Annual Forum, Washington, D. C., May 1994.

${ }^{19}$ Bousman, W. G., and Kufeld, R. M., "UH-60A Airloads Catalog,"NASA TM-2005-212827, 2005.

${ }^{20}$ Norman, T. R., Peterson, R. L., Maier, T. H., and Yeo, H., "Evaluation of Wind Tunnel and Scaling Effects With the UH60 A Airloads Rotor," American Helicopter Society $68^{\text {th }}$ Annual Forum, Fort Worth, TX, May 2012.

${ }^{21}$ Romander, E., Norman, T. R., and Chang, I-C., "Correlating Coupled CFD Simulation With Wind Tunnel Test for the FullScale UH-60A Airloads Rotor," American Helicopter Society 67 ${ }^{\text {th }}$ Anmual Forum, Virginia Beach, VA, May 2011.

${ }^{22}$ Yeo, H. and Romander, E., "Loads Correlation of a Full-Scale UH-60A Airloads Rotor in a Wind Tunnel," American Helicopter Society $68^{\text {th }}$ Annual Forum, Fort Worth, TX, May 2012. 
${ }^{23}$ Chang, I-C., Romander, E. A., Potsdam, M., and Yeo, H., "Airloads Prediction of a UH-60A Rotor Inside the 40- by 80 Foot Wind Tunnel," American Helicopter Society Specialist's Conference on Aeromechanics, San Francisco, CA, January 2010.

${ }^{24}$ Spalart, P. R. and Allmaras, S. R., "A One-Equation Turbulence Model for Aerodynamic Flows," AIAA 92-0439, AIAA $30^{\text {th }}$ Aerospace Sciences Meeting and Exhibit, Reno, NV, January 1992.

${ }^{25}$ Rogers, S. E., and Roth K., "Validation of Computed High-Lift Flows With Significant Wind-Tunnel Effects," AIAA Journal, Vol. 39, No. 10, October 2001.

${ }^{26}$ Barlow, J. B., Rae, W. H., Pope, A., Low-Speed Wind Tunnel Testing, $3^{\text {rd }}$ Edition, John Wiley \& Sons, 1999.

${ }^{27}$ Johnson, W., and Silva, F., "Rotor Data Reduction System for the NFAC," NASA-Ames Research Center, 1986.

${ }^{28}$ Chaderjian, N. H., and Buning, P. G., "High Resolution Navier-Stokes Simulation of Rotor Wakes," American Helicopter Society $67^{\text {th }}$ Annual Forum, Virginia Beach, VA May 2011.

Table 1. Trim conditions for selected data points in speed sweep (Run 52)

\begin{tabular}{|l|l|l|l|l|l|}
\hline Point & $\mathrm{M}_{\text {tip }}$ & $\mu$ & $\mathrm{C}_{\mathrm{t}} / \sigma$ & $\alpha_{\mathrm{s}}(\mathrm{deg})$ & $\alpha_{\mathrm{c}}(\mathrm{deg})$ \\
\hline 15 & 0.65 & 0.15 & 0.09 & -1.9 & 0.9 \\
\hline 20 & 0.65 & 0.2 & 0.09 & -1.9 & -0.3 \\
\hline 30 & 0.65 & 0.3 & 0.09 & -4.2 & -3.49 \\
\hline 41 & 0.65 & 0.37 & 0.09 & -7.2 & -6.74 \\
\hline 51 & 0.65 & 0.4 & 0.09 & -8.0 & -7.6 \\
\hline
\end{tabular}

Table 2. Trim conditions for selected data points in thrust sweep (Run 45)

\begin{tabular}{|l|l|l|l|l|l|}
\hline Point & $\mathrm{M}_{\text {tip }}$ & $\mu$ & $\mathrm{C}_{\mathrm{t}} / \sigma$ & $\alpha_{\mathrm{s}}(\mathrm{deg})$ & $\alpha_{\mathrm{c}}(\mathrm{deg})$ \\
\hline 30 & 0.625 & 0.3 & 0.06 & 0.0 & 0.47 \\
\hline 32 & 0.625 & 0.3 & 0.08 & 0.0 & 0.63 \\
\hline 33 & 0.625 & 0.3 & 0.09 & 0.0 & 0.70 \\
\hline 35 & 0.625 & 0.3 & 0.1104 & 0.0 & 0.86 \\
\hline 37 & 0.625 & 0.3 & 0.1253 & 0.0 & 0.98 \\
\hline 38 & 0.625 & 0.3 & 0.1255 & 0.0 & 0.98 \\
\hline
\end{tabular}

9

American Institute of Aeronautics and Astronautics 


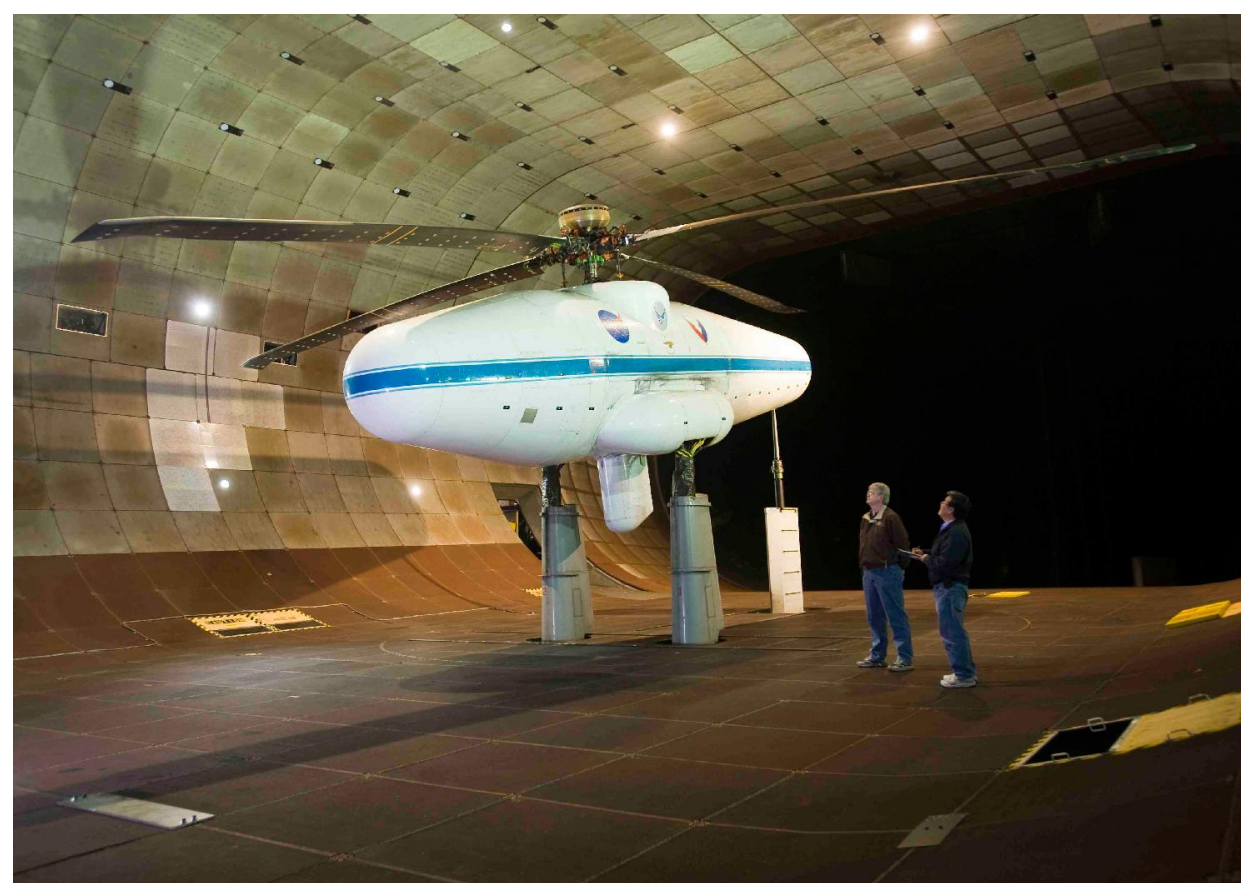

Figure 1. UH-60A Airloads rotor mounted on Large Rotor Test Apparatus in 40- by 80-Foot Wind Tunnel.

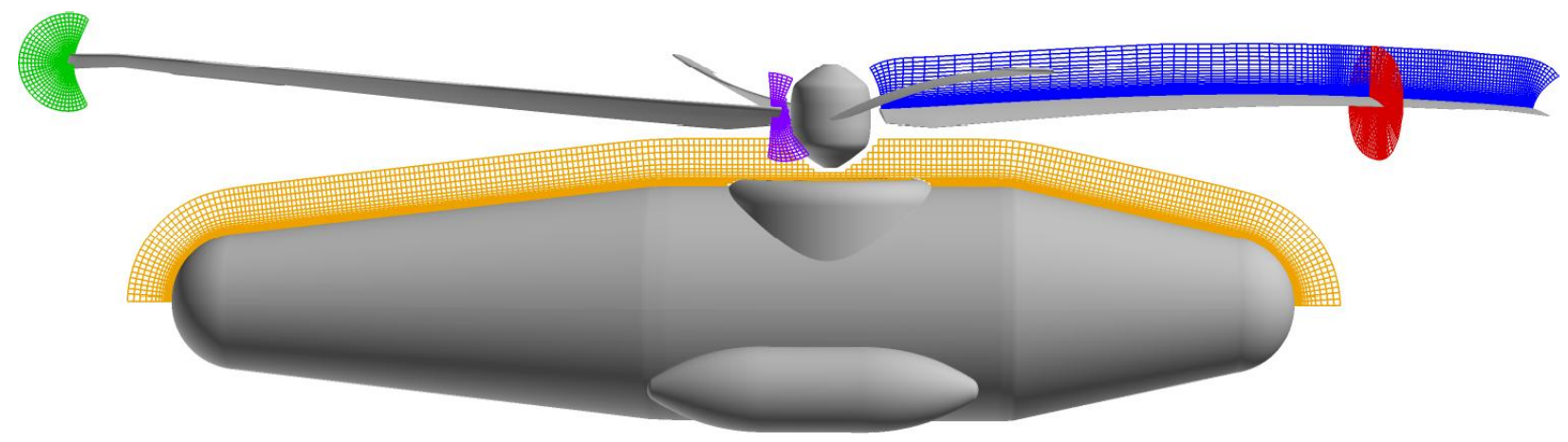

Figure 2. Near-body grid set for rotor with LTRA (some points removed for clarity). 


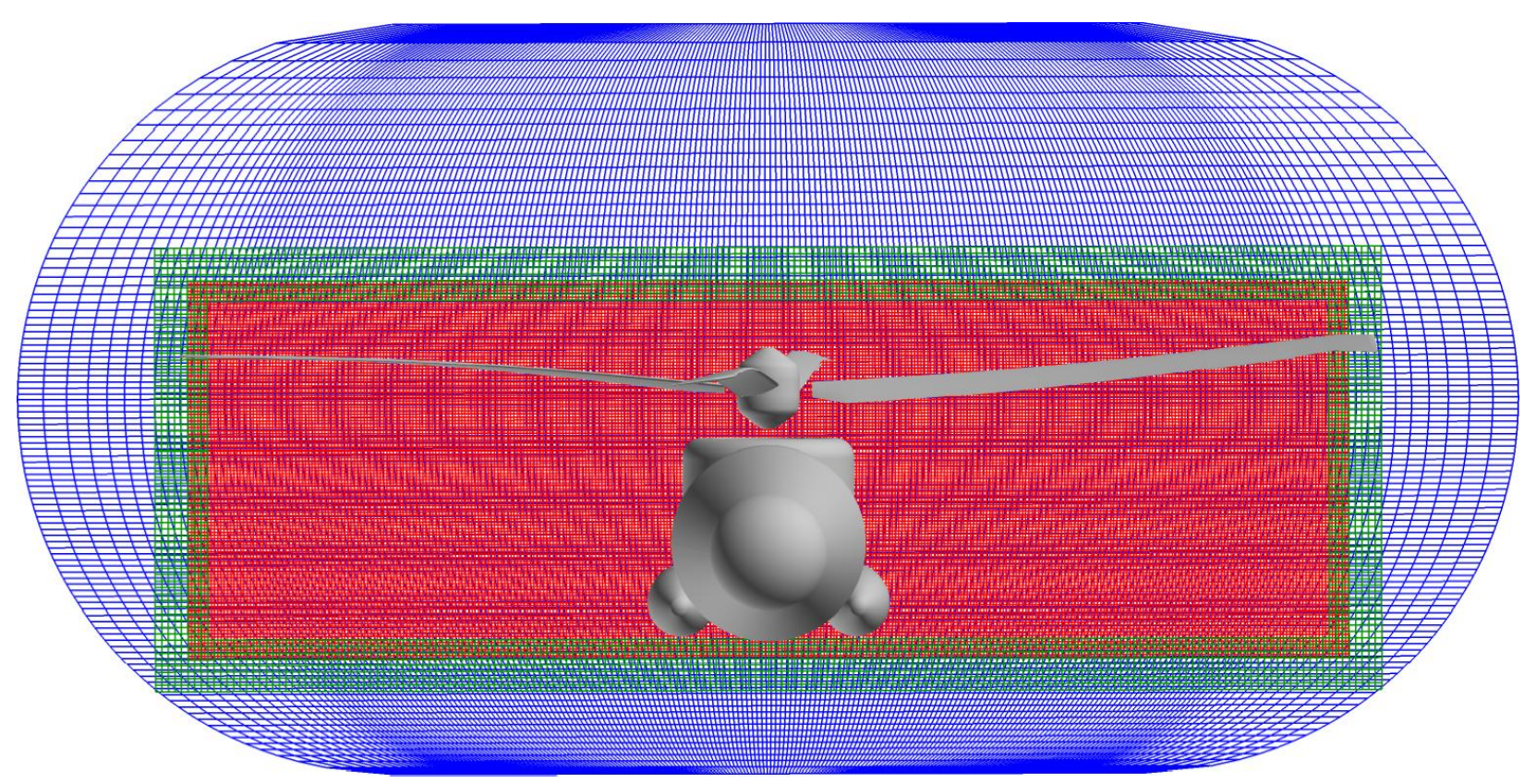

Figure 3. Transverse cut through off-body grids showing level 1 grid (red), level 2 grid (green), and wind tunnel grid (blue).

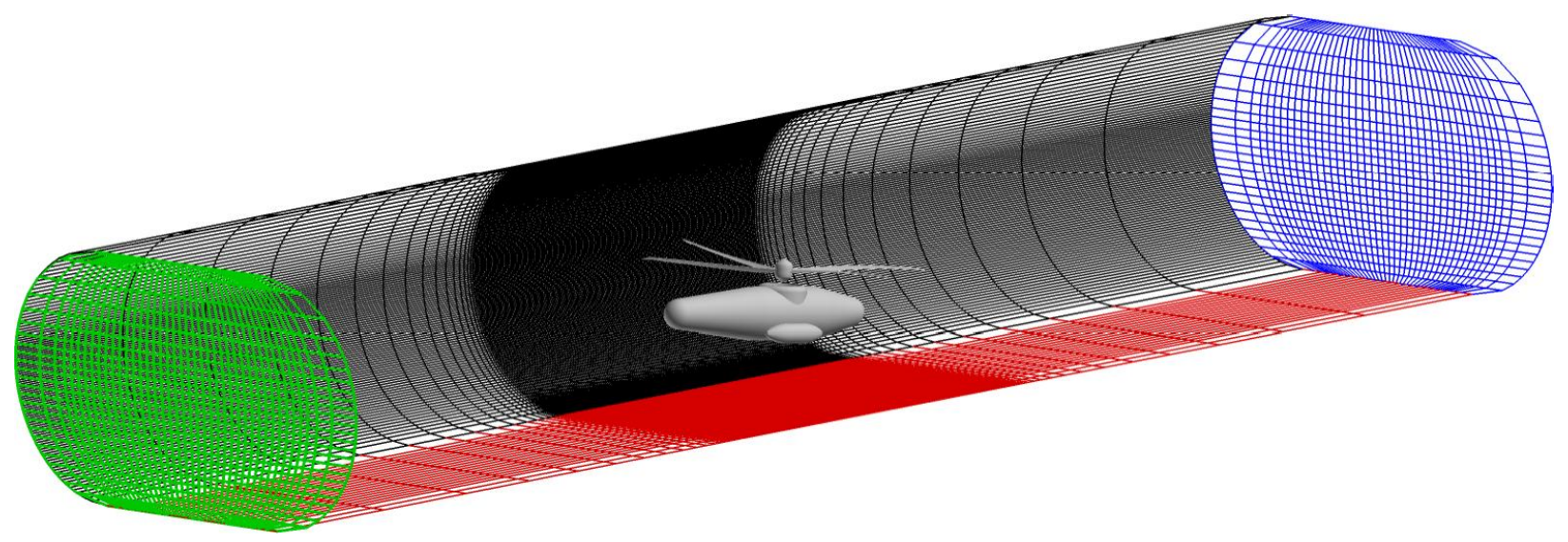

Figure 4. Off-body grid set illustrating full wind tunnel grid (level 1 and 2 grids not shown and some points removed for clarity.). 

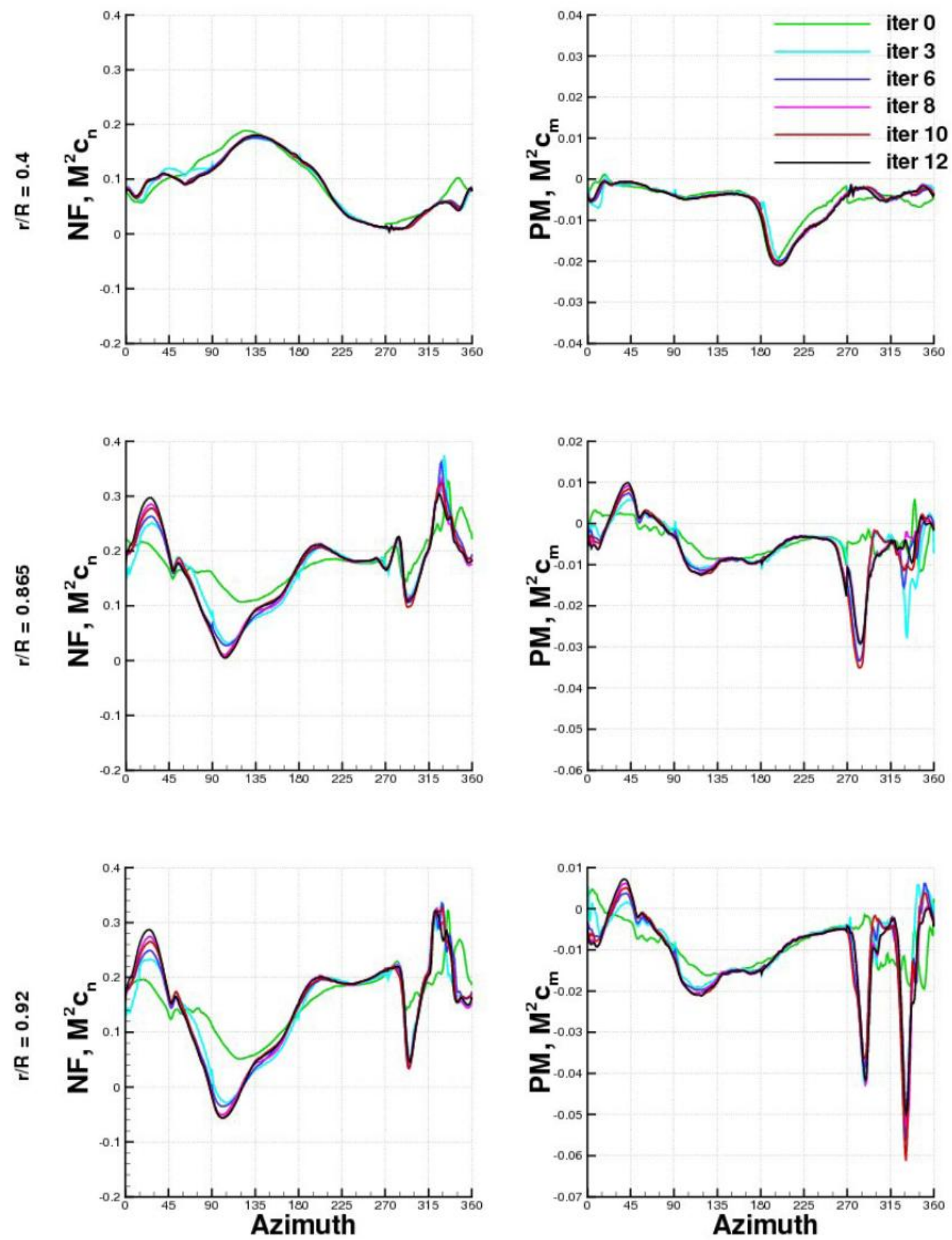

Figure 5. OVERFLOW2 airloads convergence history of direct rotor/wind tunnel modeling. $M_{\text {tip }}=0.625$, $\mu=0.3, \alpha_{s}=0.0^{\circ}, C_{t} / \sigma=0.1255$.

12

American Institute of Aeronautics and Astronautics 


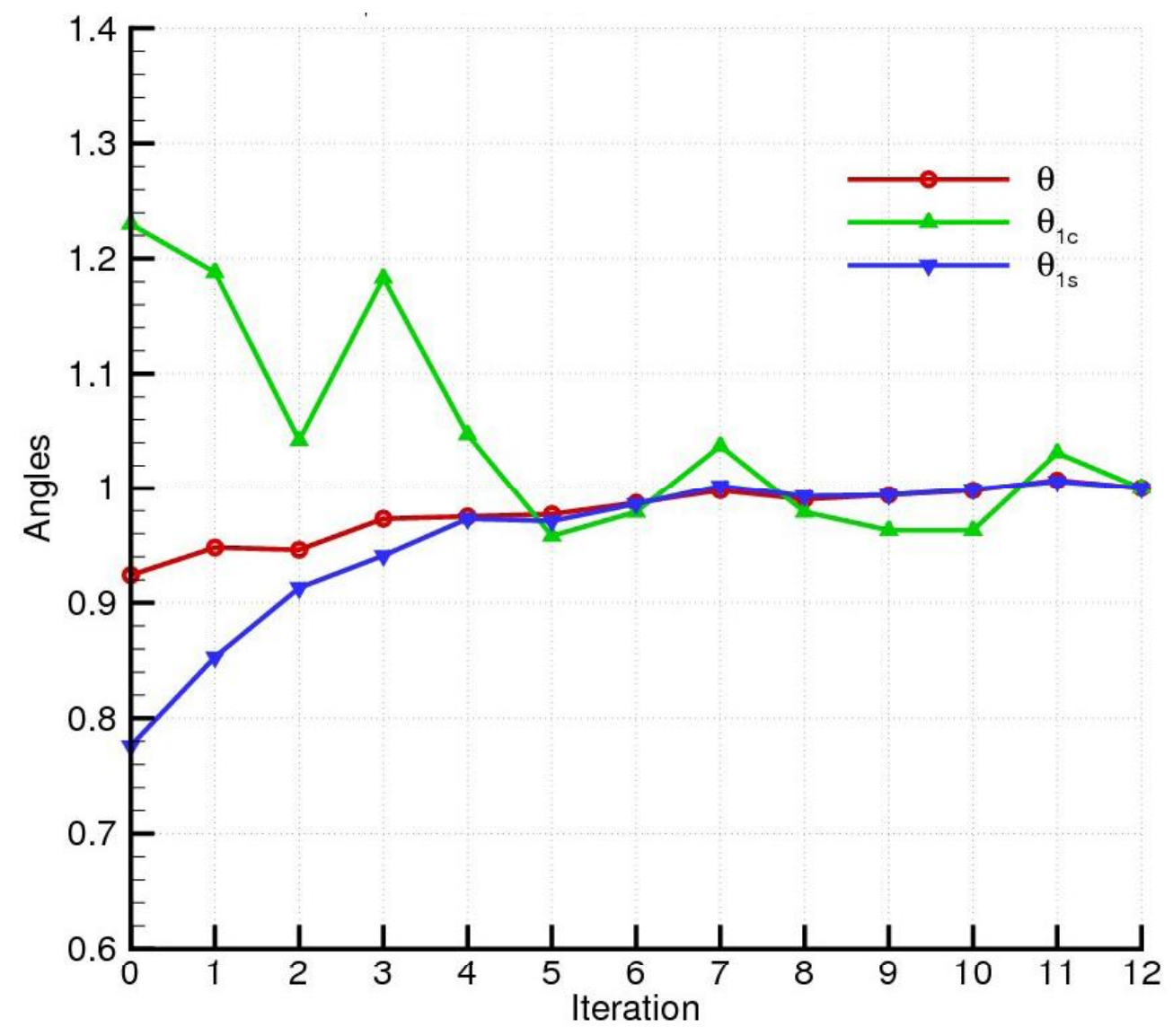

Figure 6. CAMRAD II controls convergence history of direct rotor/wind tunnel modeling. $\mathrm{M}_{\mathrm{tip}}=\mathbf{0 . 6 2 5}, \boldsymbol{\mu}=\mathbf{0 . 3}$, $\alpha_{\mathrm{s}}=0.0^{\circ}, \mathrm{C}_{\mathrm{t}} / \sigma=0.1255$. 

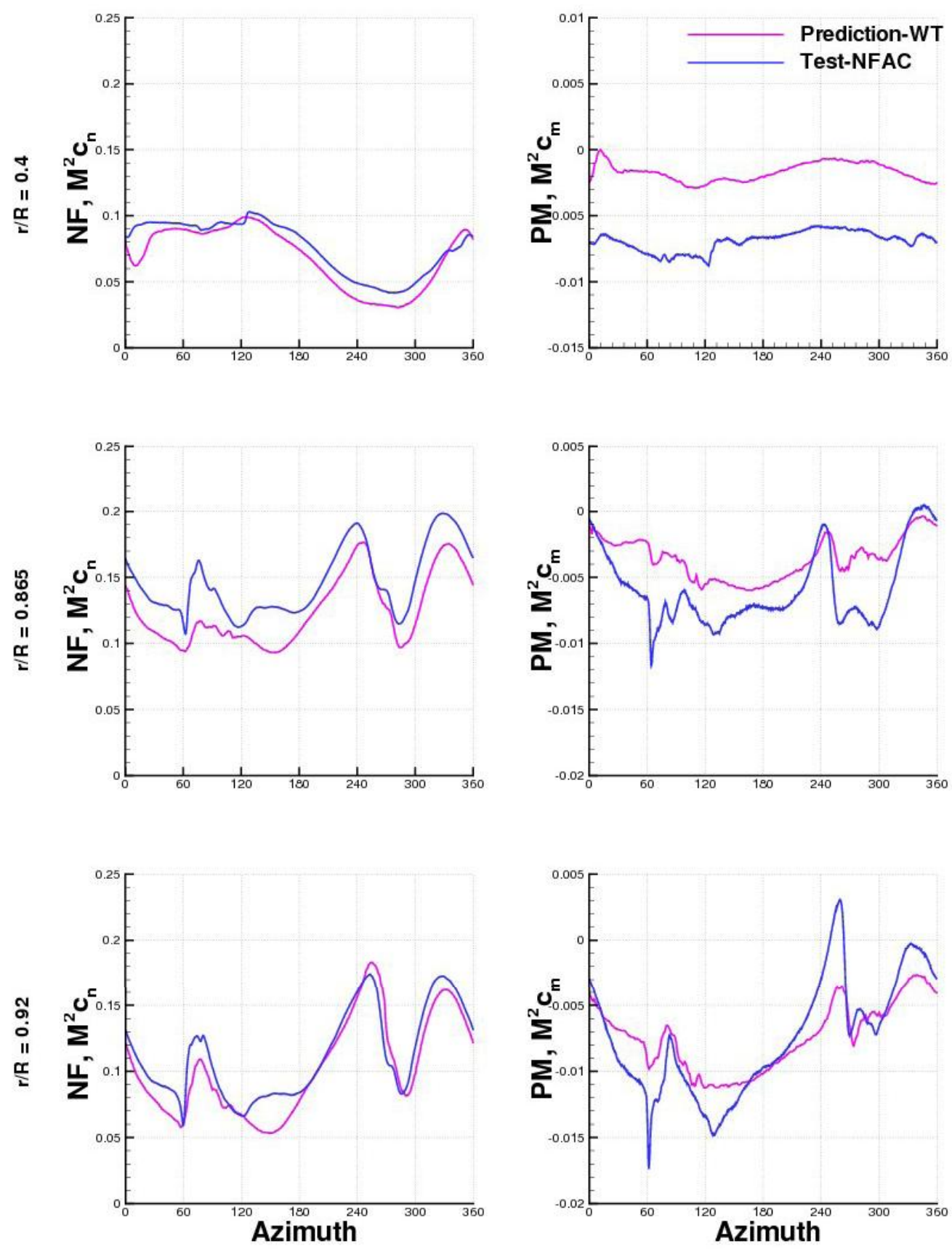

Figure 7. Comparison of predictions of rotor/wind tunnel simulation (Prediction-WT) and NFAC test data (Test-NFAC). $M_{\text {tip }}=0.65, \mu=0.15, \alpha_{s}=-1.9^{\circ}, C_{t} / \sigma=0.09$. 

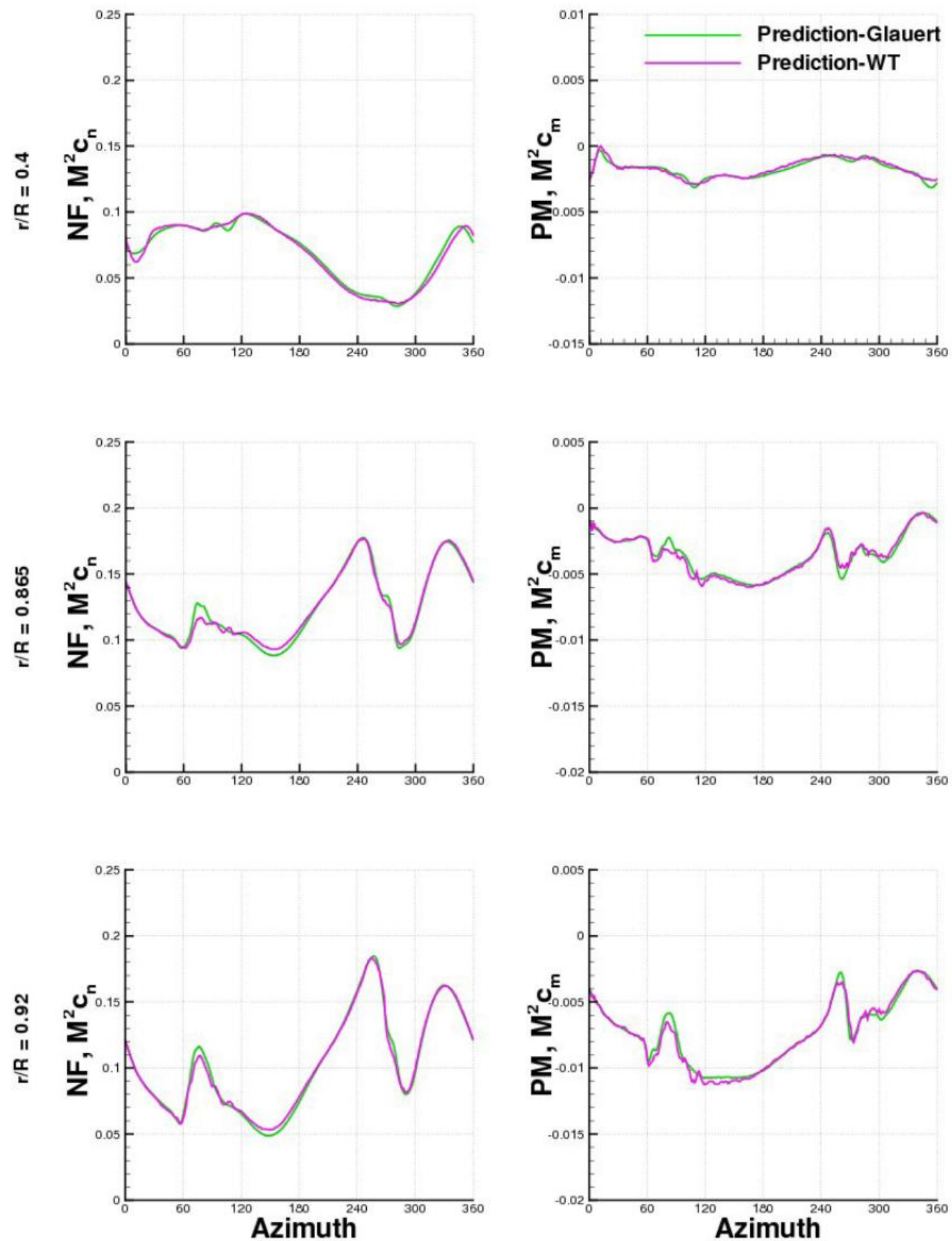

Figure 8. Comparison of predictions of free-air rotor only simulation (Prediction-Glauert) and rotor/wind tunnel simulation (Prediction-WT). $M_{t i p}=0.65, \mu=0.15, \alpha_{s}=-1.9^{\circ}, \alpha_{c}=0.9^{\circ}, C_{t} / \sigma=0.09$.

15

American Institute of Aeronautics and Astronautics 

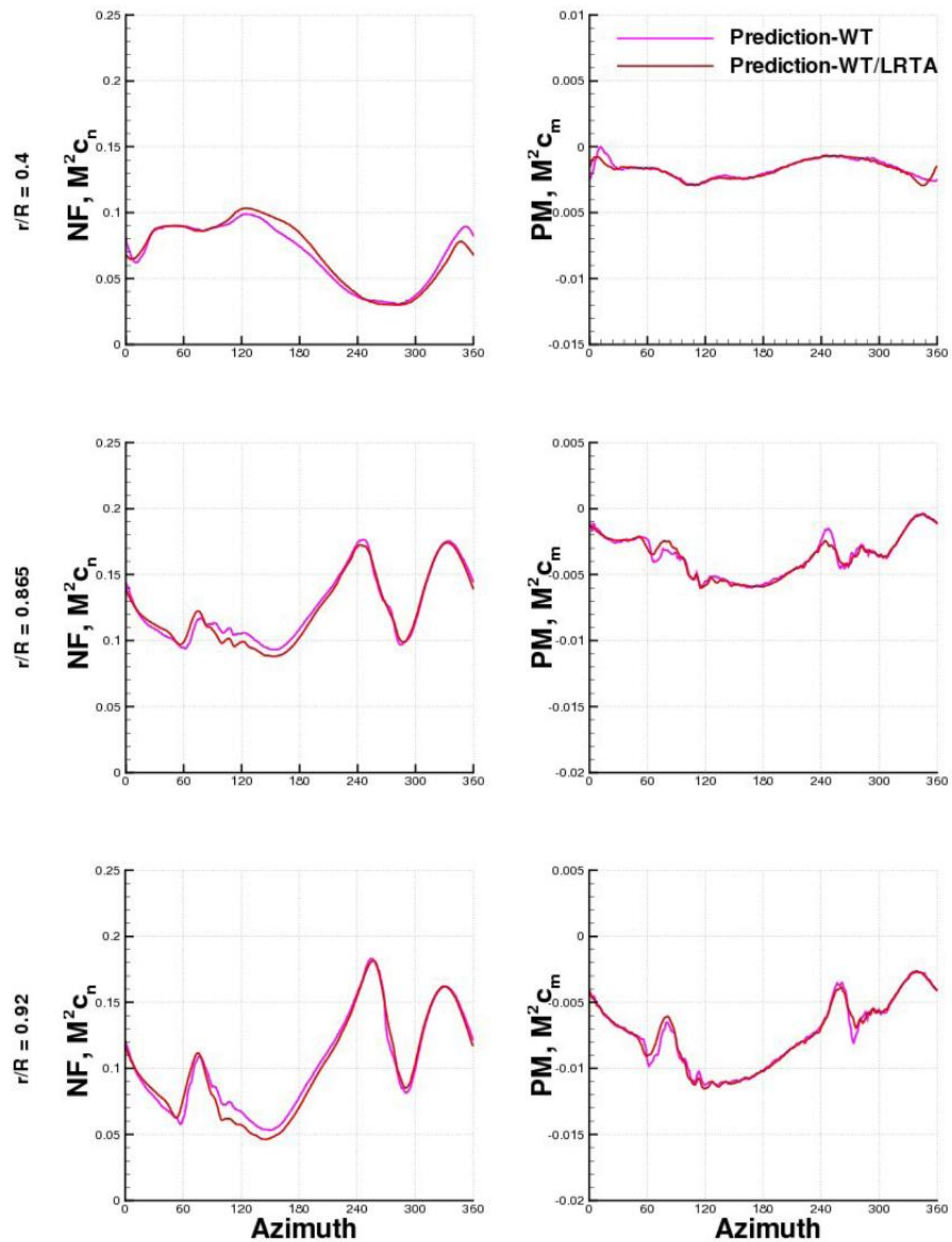

Figure 9. Comparison of predictions of rotor/wind tunnel simulation (Prediction-WT) and rotor/LRTA/wind tunnel simulation (Prediction-WT/LRTA). $M_{\text {tip }}=0.65, \mu=0.15, \alpha_{s}=-1.9^{\circ}, C_{t} / \sigma=0.09$.

16

American Institute of Aeronautics and Astronautics 

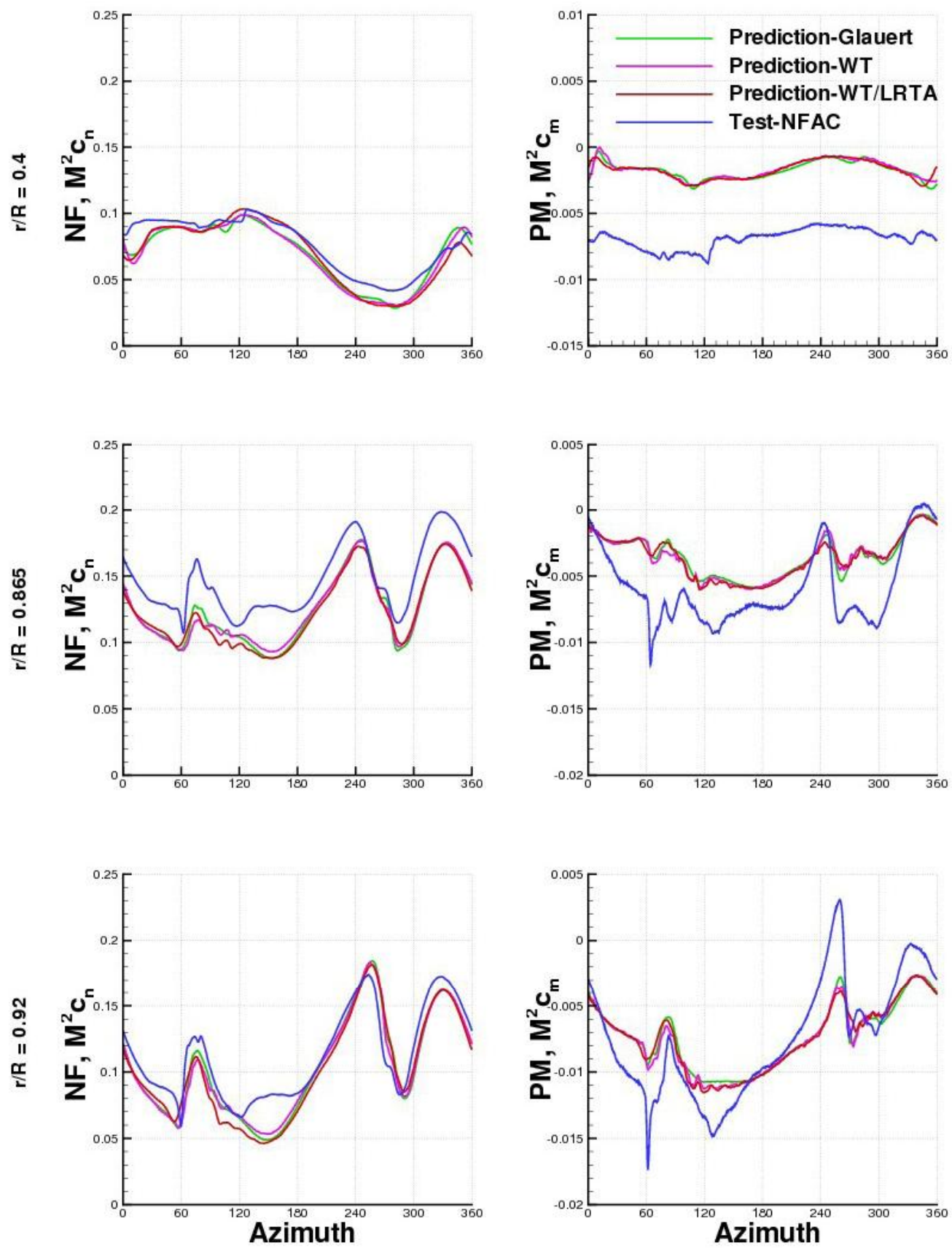

Figure 10. Comparison of predictions of free-air rotor only simulation (Prediction-Glauert), rotor/wind tunnel simulation (Prediction-WT), rotor/LRTA/wind tunnel simulation (Prediction-WT/LRTA) and NFAC test data (Test-NFAC). $M_{\text {tip }}=0.65, \mu=0.15, \alpha_{s}=-1.9^{\circ}, \alpha_{c}=0.9^{\circ}, C_{t} / \sigma=0.09$. 

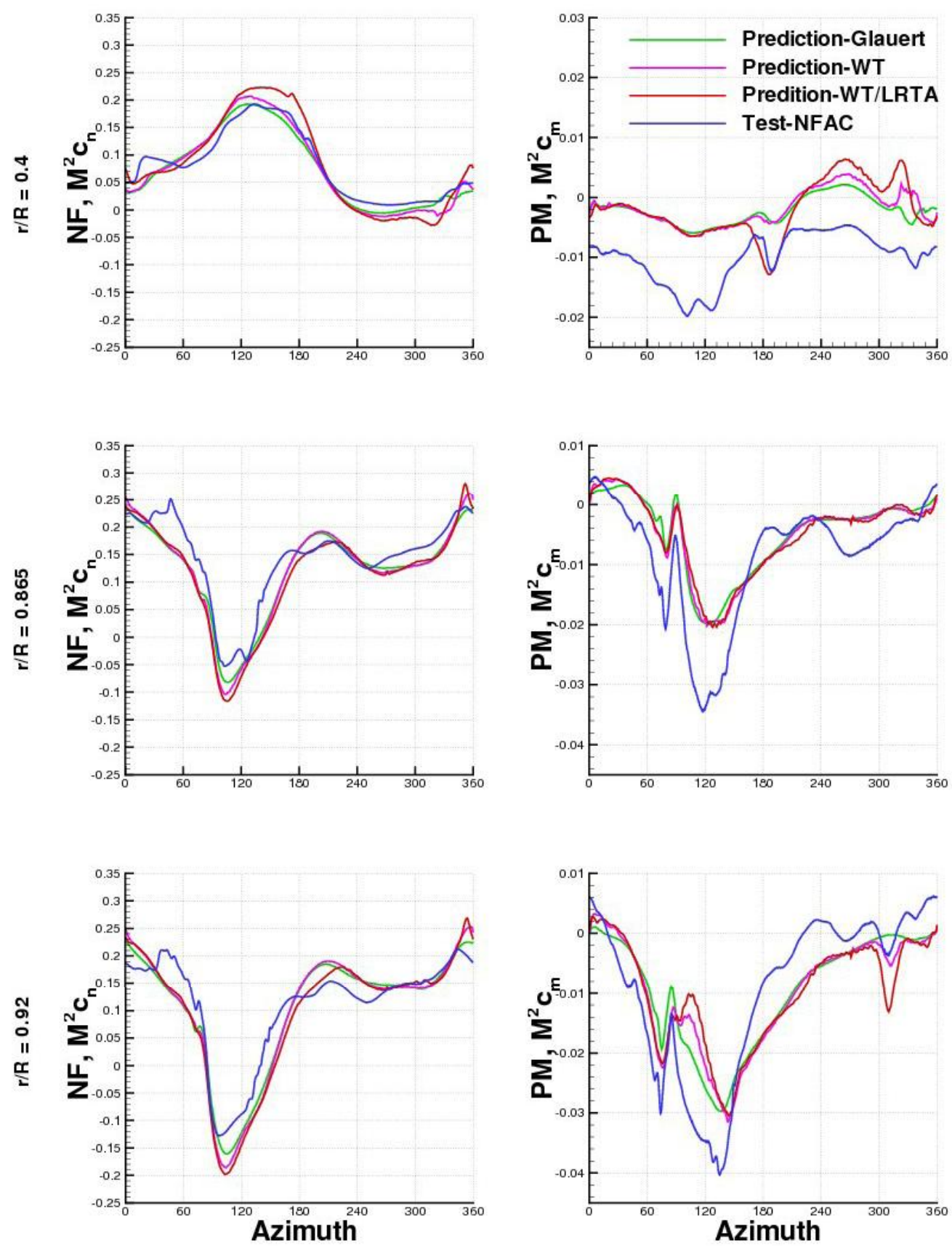

Figure 11. Comparison of predictions of free-air rotor only simulation (Prediction-Glauert), rotor/wind tunnel simulation (Prediction-WT), rotor/LRTA/wind tunnel simulation (Prediction-WT/LRTA) and NFAC test data (Test-NFAC). $M_{\text {tip }}=0.65, \mu=0.4, \alpha_{s}=-8.0^{\circ}, \alpha_{c}=-7.6^{\circ}, C_{t} / \sigma=0.09$. 

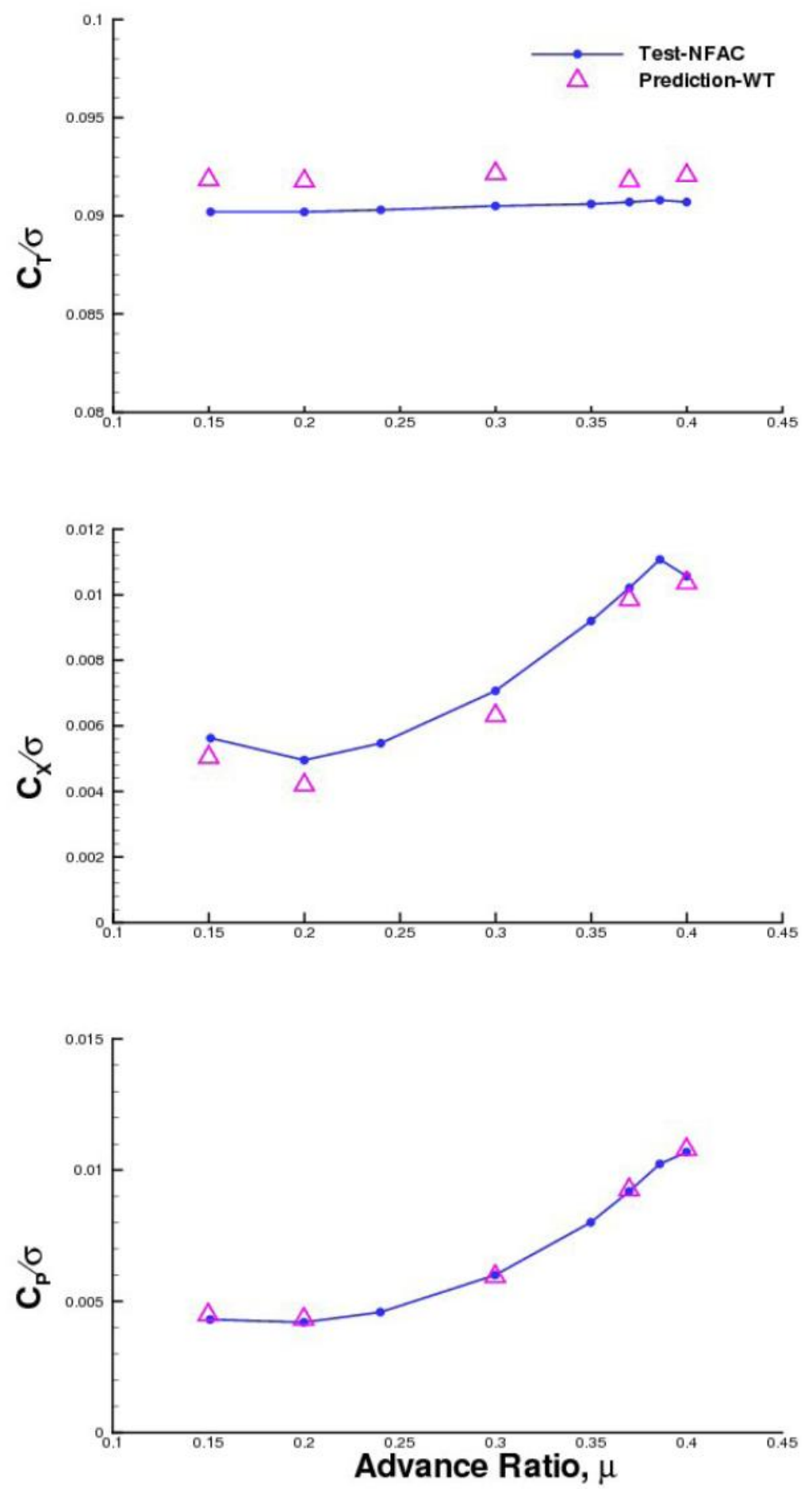

Figure 12. Comparison of predicted performance results (thrust, propulsive force, and power) of rotor/wind tunnel simulation (Prediction-WT) and NFAC test data (Test-NFAC) for the speed sweep. $M_{\text {tip }}=0.65$, $\mathrm{C}_{\mathrm{t}} / \boldsymbol{\sigma}=\mathbf{0 . 0 9}$.

19

American Institute of Aeronautics and Astronautics 

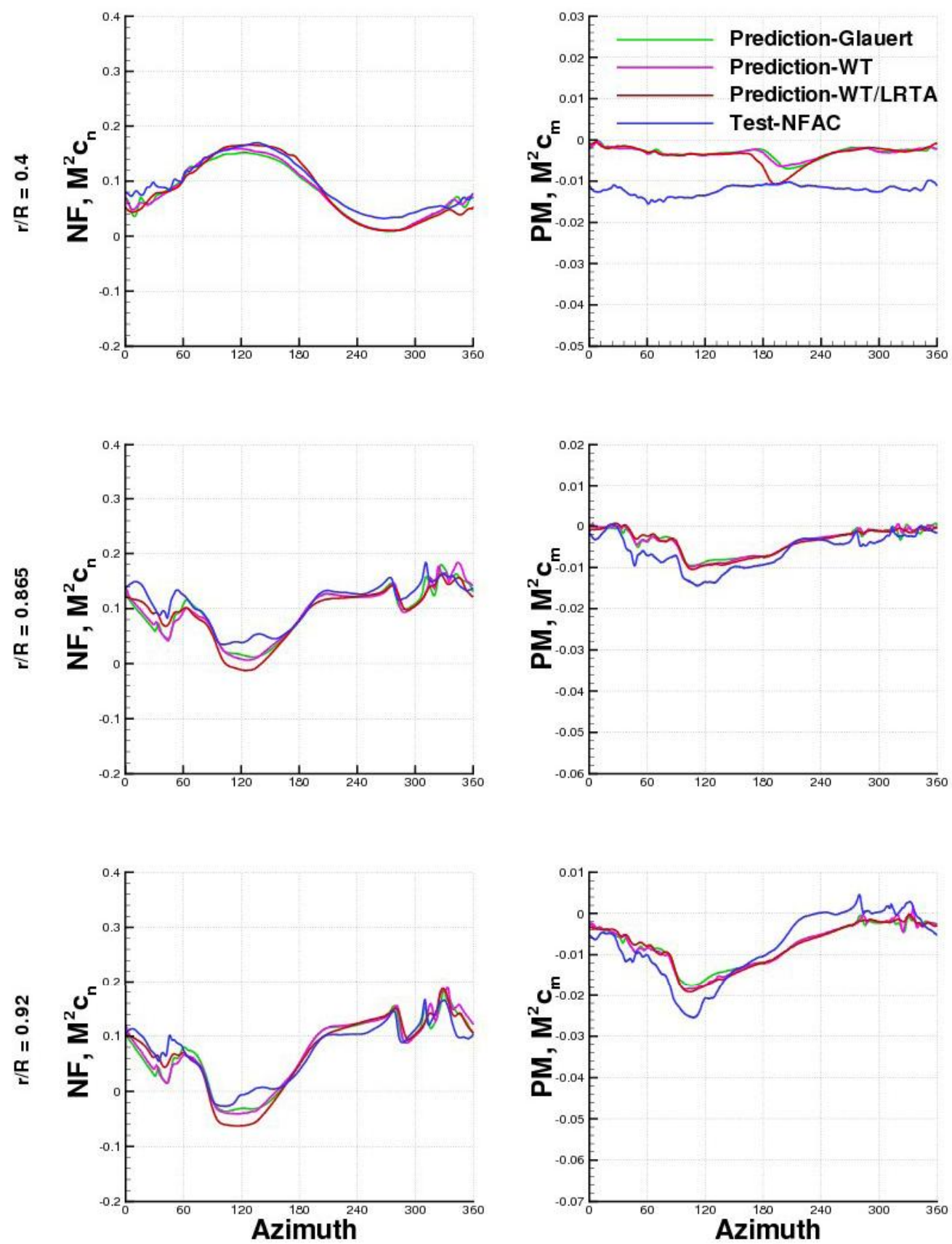

Figure 13. Comparison of predictions of free-air rotor only simulation (Prediction-Glauert), rotor/wind tunnel simulation (Prediction-WT), rotor/LRTA/wind tunnel simulation (Prediction-WT/LRTA) and NFAC test data (Test-NFAC). $M_{\text {tip }}=0.625, \mu=0.3, \alpha_{s}=0.0^{\circ}, \alpha_{c}=0.7^{\circ}, C_{t} / \sigma=0.09$. 

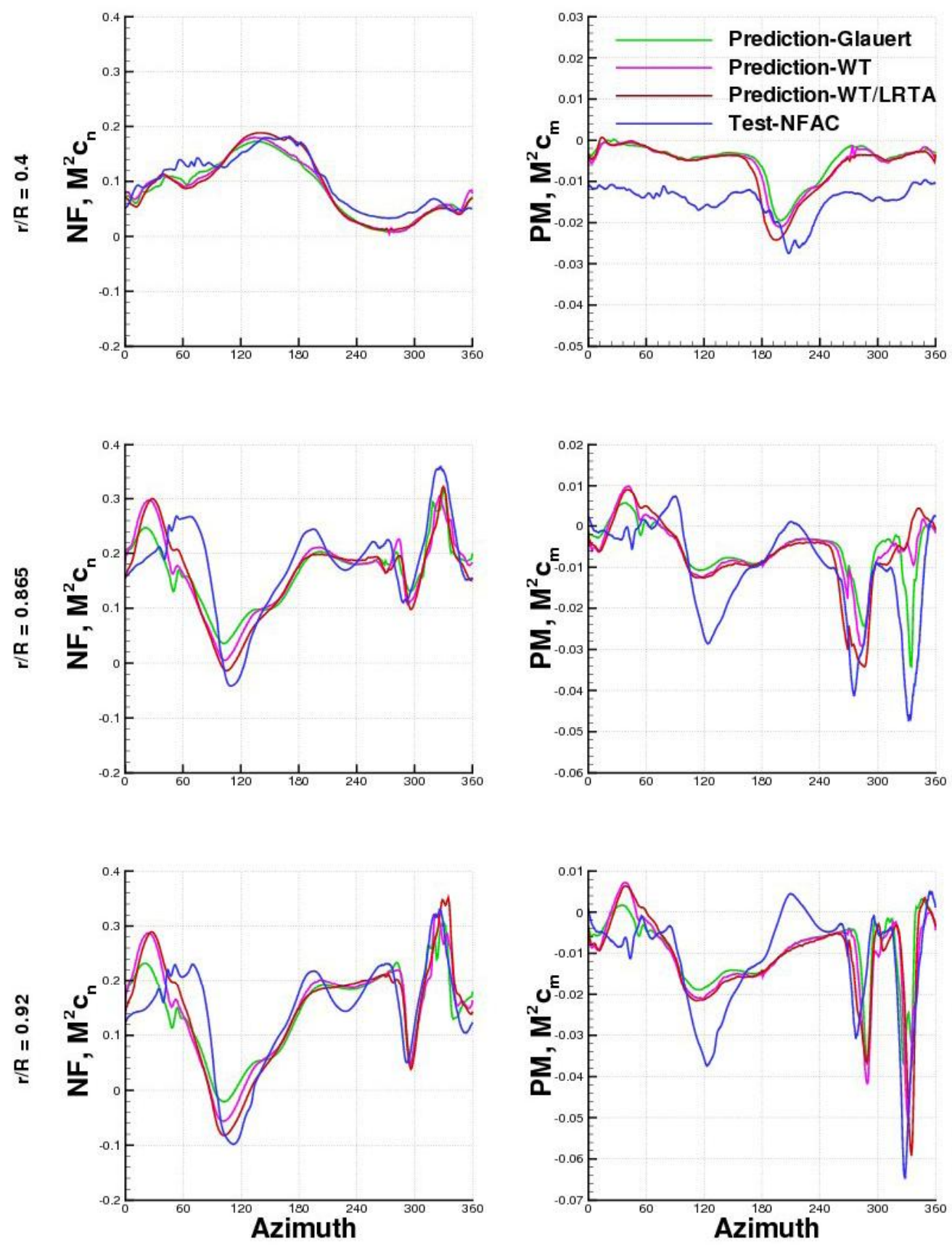

Figure 14. Comparison of predictions of free-air rotor only simulation (Prediction-Glauert), rotor/wind tunnel simulation (Prediction-WT), rotor/LRTA/wind tunnel simulation (Prediction-WT/LRTA) and NFAC test data (Test-NFAC). $M_{\text {tip }}=0.625, \mu=0.3, \alpha_{s}=0.0^{\circ}, \alpha_{c}=0.98^{\circ}, C_{t} / \sigma=0.1255$. 

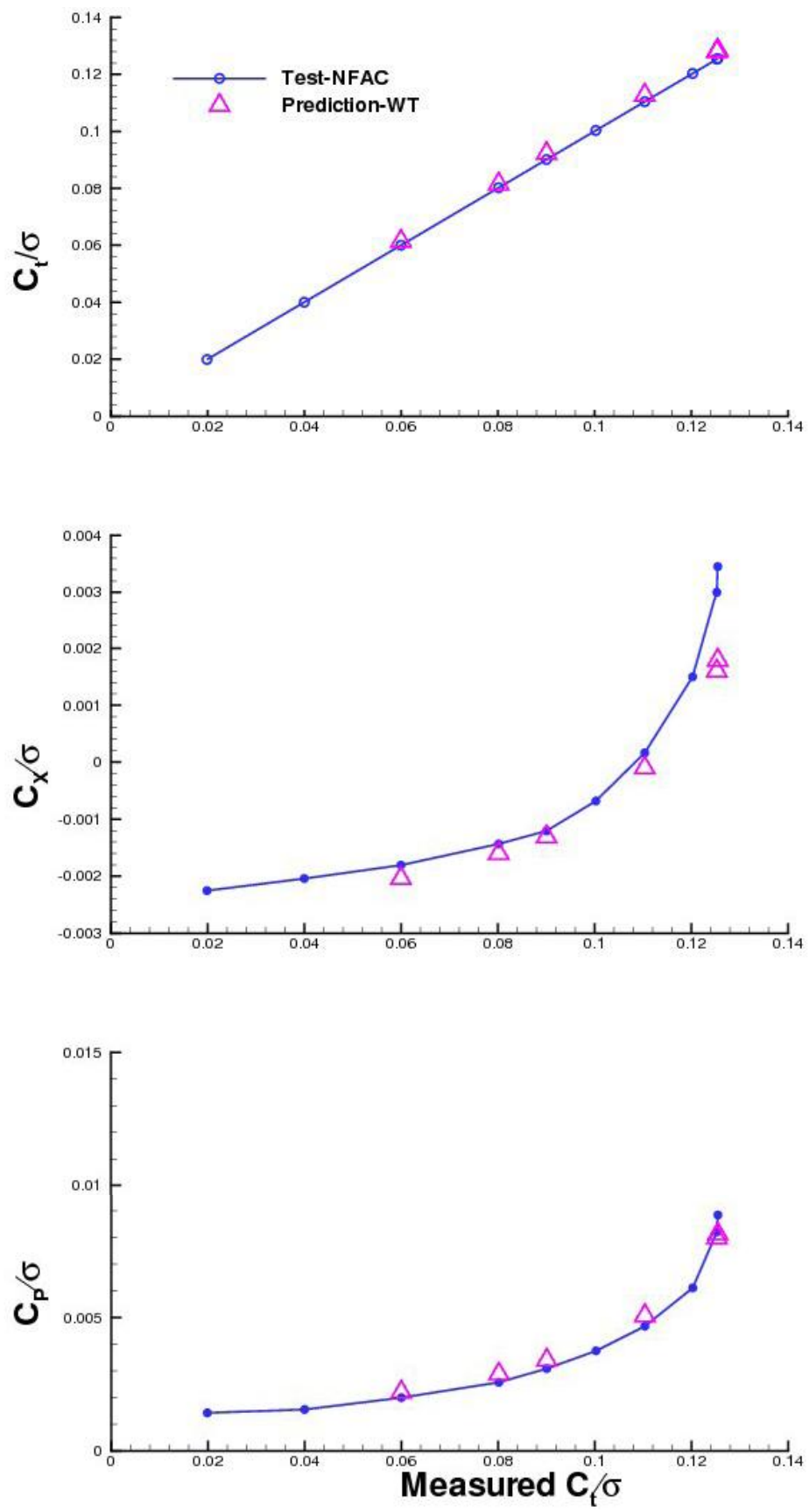

Figure 15. Comparison of predicted performance results (thrust, propulsive force, and power) of rotor/wind tunnel simulation (Prediction-WT) and NFAC test data (Test-NFAC) for the thrust sweep. $M_{\text {tip }}=0.625, \mu=0.3$, $\boldsymbol{\alpha}_{\mathrm{s}}=\mathbf{0 . 0 ^ { \circ }}$. 

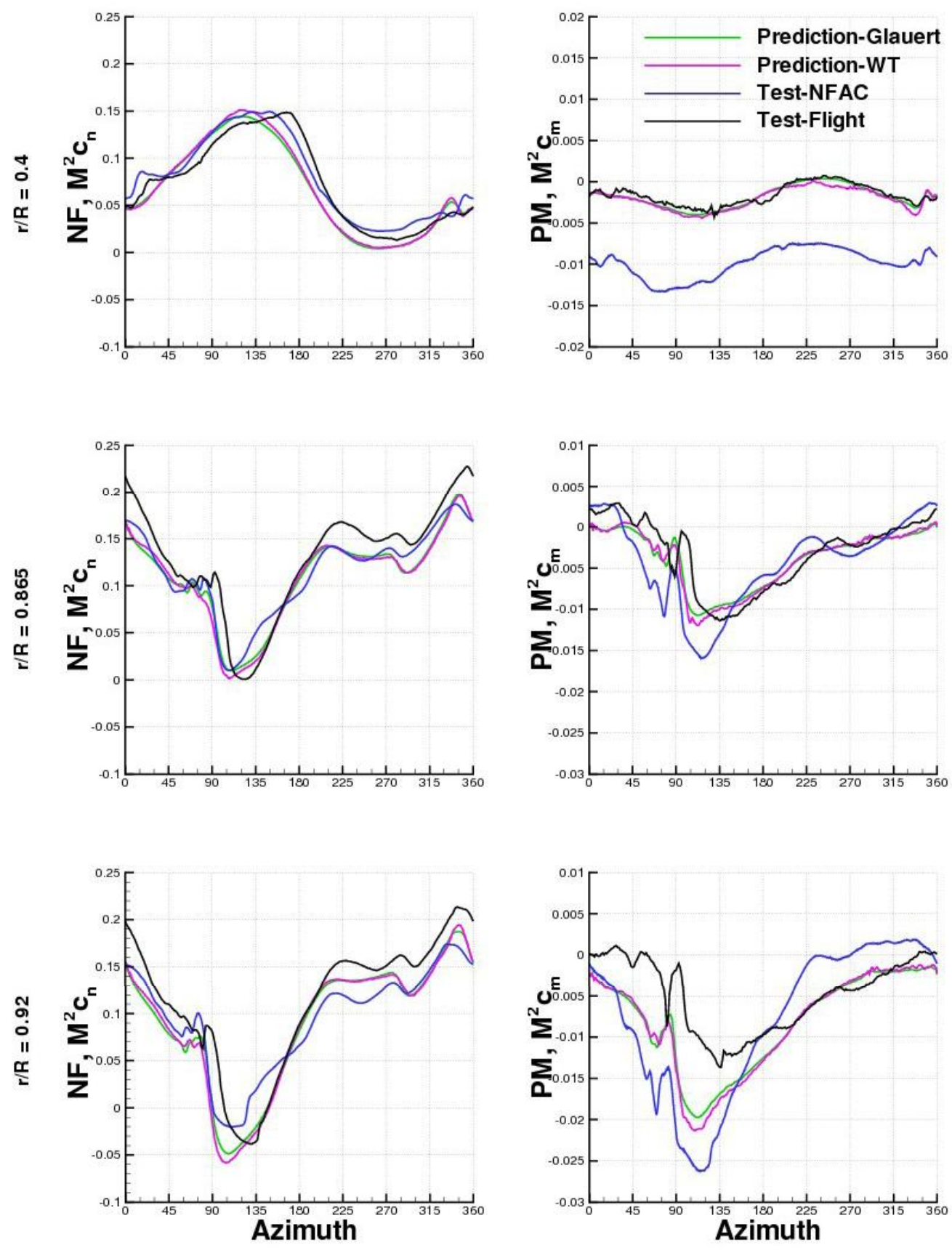

Figure 16. Comparison of predictions of free-air rotor only simulation (Prediction-Glauert), rotor/wind tunnel simulation (Prediction-WT), NFAC test data (Test-NFAC) and Airloads flight test (Test-Flight) for the matched flight test condition. $M_{\text {tip }}=0.637, \mu=0.3, \alpha_{s}=-4.8^{\circ}, \alpha_{c}=-4.2^{\circ}, C_{t} / \sigma=0.087$. 